\title{
Behaviour of fibre-reinforced cemented sand under flexural tensile stress
}

\author{
Thaís Martins de Paula ${ }^{1, *}$, Nilo Cesar Consoli ${ }^{1}$, Lucas Festugato ${ }^{1}$, Filipe Favretto ${ }^{1}$, and João Victor Linch Daronco ${ }^{1}$ \\ ${ }^{1}$ Federal University of Rio Grande do Sul (UFRGS), School of Engineering, Porto Alegre, Brazil
}

\begin{abstract}
In soil improvement, the insertion of cement to the soil matrix provides an increase in strength and rigidity of the material, whereas fibre addition provides an increase in ductility, reducing post-peak loss in strength. This research aims to experimentally analyse the mechanical behaviour of unreinforced and fibre-reinforced cemented sands under flexural tensile monotonic loading conditions. In order to do so, an experimental program was planned using silty sand (Arenito Botucatu), early strength Portland cement - CPIII, and polypropylene fibres $24 \mathrm{~mm}$ long and 0.023 $\mathrm{mm}$ thick. Three different dry unit weights $\left(\gamma_{\mathrm{d}}\right)\left(18,19\right.$ and $\left.19.7 \mathrm{kN} / \mathrm{m}^{3}\right)$, three cement contents $(3,5$ and $7 \%$ ), and two fibre contents $(0$ and $0.5 \%)$ were chosen. Analysing the results, an increase in cement content generates an increase in flexural strength $\left(\mathrm{q}_{\mathrm{f}}\right)$ for all concentrations and the increase in $\gamma_{\mathrm{d}}$ generated smaller $\mathrm{q}_{\mathrm{f}}$ gains, especially for lower cement contents. The addition of fibres generated a $\mathrm{q}_{\mathrm{f}}$ increase for lower $\gamma_{\mathrm{d}}$ but at higher $\gamma_{\mathrm{d}}$ there was a reduction in the influence of fibre addition on strength gain. The reduction can be attributed to an entanglement of the fibres in higher compaction strengths, disrupting the formation of cementitious bonds. However, based on a qualitative assessment, there was a noticeable reduction in post-peak strength loss due to fibre insertion. The parameter porosity/volumetric cement content $\left(\eta / \mathrm{Civ}_{\mathrm{iv}}{ }^{0.28}\right)$ was considered suitable to predict the $\mathrm{q}_{\mathrm{f}}$ mechanical behaviour of the studied composite.
\end{abstract}

\section{Introduction}

Soils have an intrinsic variability regarding their characteristics, which can lead to many design issues in engineering endeavours. A possible solution is to improve the mechanical properties of the soil through the insertion of additives, such as cementing agents, pozzolans, fibres, etc. Thus, this research aims to evaluate the mechanical properties of Portland cement and polypropylene fibres in a silty sand soil when subjected to flexural tensile loading.

Soil improvement through cement addition increases the resistance and stiffness of the mixture. However, it also increases brittleness, leading the enhanced soil to fail in a brittle way [1]. On the other hand, fibre addition, which is essentially a tension-resisting filament, increases the ductility and durability of the reinforced soil without compromising the strength of the composite. The addition of randomly oriented fibres to cemented soils generates a composite that has as mechanical characteristics strength, ductility, and post-rupture load bearing capacity $[2,3]$. Such composite soils present a relatively low cost alternative solution in traditional geotechnical designs (e.g. pavement construction, when there are no granular bases available near the site; or foundation construction on low bearing capacity soils, when the deep foundation costs would be prohibitive [4]).
Most of the experimental research presented so far regarding the mechanical behaviour of fibre-reinforced cemented sands entails the analysis of these composites under compression or split tensile loading $[2,5,6,7,8]$. The mechanical behaviour of fibre-reinforced cemented sands under flexural tensile loading (where failure occurs only due to tensile stress) has not been studied as extensively $[9,10]$. Therefore, there is still the need for the geotechnical community to further research this loading condition in order to have a more comprehensive understanding of the mechanical behaviour of fibrereinforced cemented soils.

\section{Experimental Program}

The research was divided in two parts. The first consisted of characterising the physical properties of the materials used in this study. The second part presented and described the methods employed in the moulding process and the flexural tensile tests that were carried out.

\subsection{Materials}

The materials used in this research were soil, cement, fibre, and water. Their characterisations are presented in the following sub-sections.

\footnotetext{
* Corresponding author: thaismartinsdepaula@gmail.com
} 


\subsubsection{Soil}

This research used residual soil known as Arenito Botucatu derived from sandstone of the Botucatu formation in southern Brazil. This soil covers an extensive economically important area. Its erodability and low bearing capacity made the study of alternative geotechnical solutions, such as soil improvement, desirable. The material was used in its natural form. Results of soil characterization are shown in Table 1 and the grain size distribution curve is presented in Fig. 1. This soil is classified as silty sand (SC) according to the Unified Soil Classification System (SUCS).

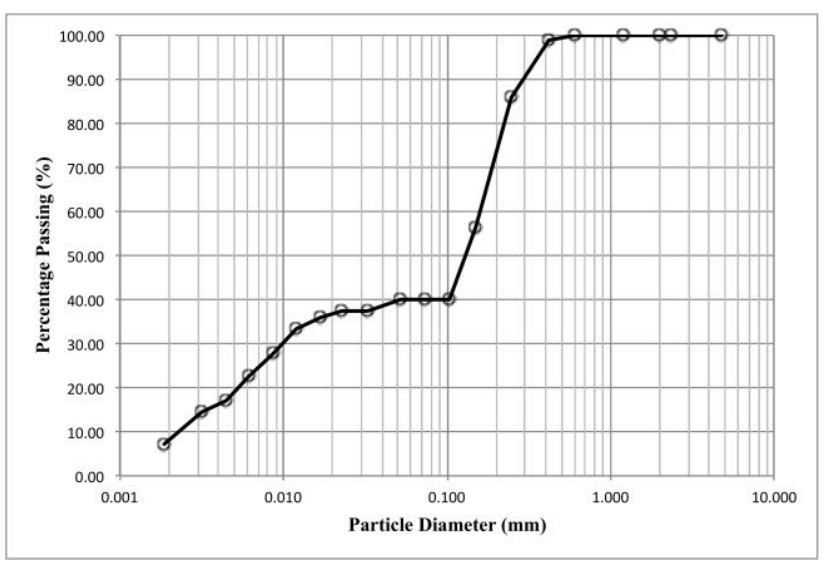

Fig. 1. Grain size distribution of Arenito Botucatu.

Table 1. Physical characterization of Arenito Botucatu.

\begin{tabular}{|c|c|}
\hline Properties & Values \\
\hline Liquid Limit (LL) & 21 \\
\hline Plasticity Limit (PL) & 17 \\
\hline Plasticity Index (PI) & 4 \\
\hline Specific gravity & 2.67 \\
\hline$\%$ Medium sand $(0.2 \mathrm{~mm}<\phi)$ & $14.15 \%$ \\
\hline$\%$ Fine sand $(0.06<\phi<0.2 \mathrm{~mm})$ & $48.82 \%$ \\
\hline$\%$ Silt $(0.002<\phi<0.06 \mathrm{~mm})$ & $29.69 \%$ \\
\hline$\%$ Clay $(\phi<0.002 \mathrm{~mm})$ & $7.35 \%$ \\
\hline Effective diameter $\left(\mathrm{D}_{10}\right)$ & $0.0027 \mathrm{~mm}$ \\
\hline Mean particle diameter $\left(\mathrm{D}_{50}\right)$ & $0.132 \mathrm{~mm}$ \\
\hline Coefficient of uniformity $\left(\mathrm{C}_{\mathrm{u}}\right)$ & 60 \\
\hline $\begin{array}{c}\text { Maximum dry unit weight for } \\
\text { intermediate Proctor compaction effort }\end{array}$ & $19.7 \mathrm{kN} / \mathrm{m}^{3}$ \\
\hline $\begin{array}{c}\text { Optimum moisture content for } \\
\text { intermediate Proctor compaction effort }\end{array}$ & $10 \%$ \\
\hline
\end{tabular}

\subsubsection{Cement}

The cementitious material used is Portland cement of high initial strength CP III. This material was chosen because of its accelerated resistance gain, reaching on average $80 \%$ of its resistance at 28 days with only 7 days of curing. The cement used has a specific gravity of 3.15.

\subsubsection{Fibre}

The polypropylene fibres used in this experimental program were produced locally for the textile industry. The dimensions of the fibre are $0.023 \mathrm{~mm}$ in diameter and $24 \mathrm{~mm}$ in length. The elastic modulus of the fibres is $3 \mathrm{GPa}$, with an ultimate tensile strength of $120 \mathrm{MPa}$ and specific gravity of 0.91 .

\subsubsection{Water}

Distilled water was used for characterization tests and specimen moulding.

\subsection{Methodology}

\subsubsection{Moulding and curing of specimens}

In order to perform flexural tensile tests, a rectangular prismatic mould with dimensions of $17 \mathrm{~cm} \times 4 \mathrm{~cm} \times 4 \mathrm{~cm}$ (length $\mathrm{x}$ depth $\mathrm{x}$ width) was used. The present research used three dry unit weights $\left(\gamma_{d}\right)\left(18,19\right.$ and $\left.19.7 \mathrm{kN} / \mathrm{m}^{3}\right)$, three cement contents $(3,5$ and $7 \%$ ), and two fibre contents $(0$ and $0.5 \%)$, resulting in 18 combinations. For each combination three samples were prepared giving a total of 54 samples. The water content $(\omega)$ was $10 \%$ and was kept constant in order to assess the influence of the porosity, cement content, and fibre addition on the tensile strength of the mixtures.

The values for dry unit weight and moisture content were chosen based on the results of a compaction test using intermediate Proctor compactive effort (26 blows per layer on the modified Proctor apparatus, equivalent to $\left.1267.5 \mathrm{~kJ} / \mathrm{m}^{3}\right)$ [11] shown in Table 1. The values of cement and fibre content were based on Consoli et al. [7].

The target $\gamma_{\mathrm{d}}$ was achieved by dividing the total mass of the mixture by the volume of the specimen. In order to maintain the required dry unit weights with varying cement and fibre contents, an appropriate mass of soil was sacrificed to make way for the additives. The amount of cement used in each sample was calculated based on the mass of dry soil for the target $\gamma_{\mathrm{d}}$. The weight of fibres used was based on the mass of dry soil and cement.

The porosity $(\eta)$ of the soil-cement-fibre composite was calculated by equation 1 , where the specific gravity of the cement is $\mathrm{G}_{\mathrm{SC}}$, of the soil is $\mathrm{G}_{\mathrm{sS}}$, and of the fibre is $\mathrm{G}_{\mathrm{sF}} . \mathrm{V}_{\mathrm{S}}$ is the total volume of the specimen, $\mathrm{C}$ is the cement content (percentage of dry weight of soil), and $\mathrm{F}$ is the fibre content (percentage of dry weight of soil plus cement).

Both non-reinforced and fibre-reinforced samples were prepared by weighing the materials with a precision of $0.01 \mathrm{~g}$. Soil and cement are hand mixed then, water was introduced and mixed until uniform. After which, for fibre-reinforced samples, the fibres were carefully added. After the mixing process, the amount necessary for the sample preparation was weighed and kept in a closed container until moulding. Subsequently, two capsules were weighed in order to determinate the moisture content of the mixture. 


$$
\begin{aligned}
\eta=100 & -\frac{100}{V_{S}} \times\left\{\left[\frac{\gamma_{d} \cdot V_{S} /\{[1+(C / 100)] \cdot[1+(F / 100)]\}}{G_{S S}}\right]+\right. \\
& {\left[\frac{\left(\gamma_{d} \cdot V_{S} /\{[1+(C / 100)] \cdot[1+(F / 100)]\}\right) \cdot(C / 100)}{G_{S}}\right]+} \\
& {\left.\left[\frac{\left(\gamma_{d} \cdot V_{S} /\{[1+(C / 100)] \cdot[1+(F / 100)]\}\right) \cdot(F / 100)}{G_{S}}\right]\right\} }
\end{aligned}
$$

The weighed material was statically compacted in a single layer using a split metal mould. Then, the specimens were measured and weighed to an accuracy of $0.01 \mathrm{~g}$ and $0.1 \mathrm{~mm}$, respectively. The samples were stored inside plastic bags to maintain moisture content and were stored in a humid room with controlled temperature of 23 $\pm 2^{\circ} \mathrm{C}$ and relative humidity above $95 \%$ for six days. On the sixth day, the samples were submerged in water kept at the same controlled temperature as the curing room to minimize suction. This procedure did not affect the cementation process given that the initial moisture content of the specimens was enough for cement hydration.

Samples were accepted for testing if the following criteria were met: the dry unit weight of the sample was $\pm 1 \%$ of the target value; the moisture content of the sample was $\pm 0.5 \%$ of the target value; and the dimensions were within $\pm 1 \mathrm{~mm}$ of the target value.

\subsubsection{Flexural tensile tests}

The third-point loading flexural tensile test followed the procedures set out in ASTM D1635 [12]. It used an automatic press with maximum capacity of $100 \mathrm{kN}$, equipped with a calibrated dynamometer ring with load capacity of $10 \mathrm{kN}$ and resolution of $0.005 \mathrm{kN}(0.5 \mathrm{kgf})$. The strain velocity was fixed at $1.14 \mathrm{~mm}$ per minute.

After the curing period, the samples were removed from the water and excess surface moisture removed just before the test was carried out. The sample was carefully placed so that the top and bottom points are properly aligned. This procedure ensures that the middle third of the sample is subjected to the tensile loading as can be observed in Fig. 2.

The ASTM D1635 [12] relates the test load with the geometric properties of the specimen to calculate the flexural strength $\left(\mathrm{q}_{\mathrm{f}}\right)$ of the material as expressed in equation 2. Where $\mathrm{P}$ is the maximum load from the test $(\mathrm{N}), \mathrm{L}$ is the span length $(\mathrm{mm}), \mathrm{b}$ is the average width $(\mathrm{mm})$ and $\mathrm{d}$ is the average depth $(\mathrm{mm})$.

$$
q_{f}=\frac{P . L}{b . d^{2}}
$$

The test result of flexural tensile strength $\left(\mathrm{q}_{\mathrm{f}}\right)$ was accepted if the difference between the same mixture samples is less than $10 \%$.

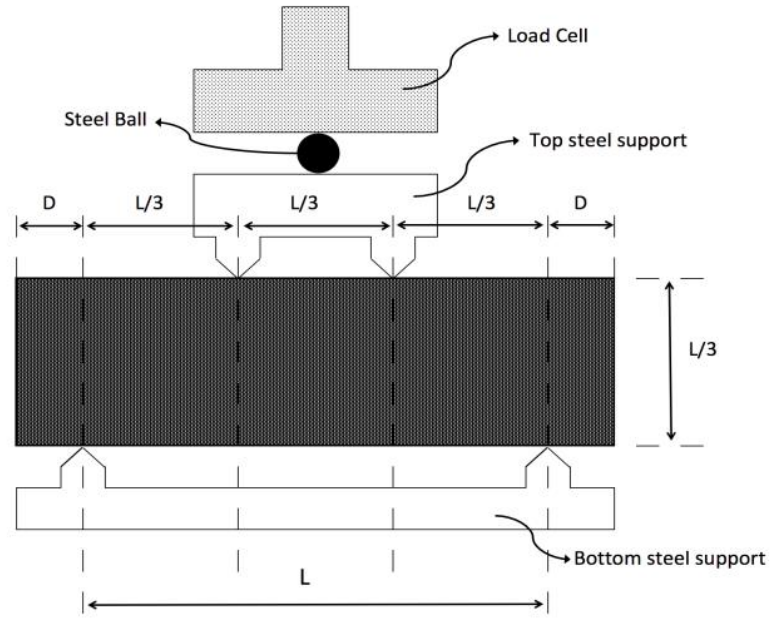

Fig. 2. Positioning of specimen on the metal supports for flexural tensile test

\section{Results and Analysis}

The results from the experimental program are presented in Tables 2 and 3 and in Fig. 3, where $\gamma_{\mathrm{d}}$ is the dry unit weight, $\mathrm{C}$ is the cement content, $\mathrm{F}$ is the fibre content, $\mathrm{q}_{\mathrm{f}}$ is the flexural tensile strength and $\mathrm{R}^{2}$ is the coefficient of determination of the data. Fig. 3 (a) displays the data for the cemented sand specimens and Fig. 3 (b) for the fibrereinforced cemented sand specimens.

As expected from previous research with Botucatu residual soil and cement $[7,13,14]$ it is observed that an increase in cement content leads to an increase in strength. The average increase in strength due to cement addition from 3 to $7 \%$ for unreinforced specimens was of 87,70 , and $119 \%$ for 18,19 and $19.7 \mathrm{kN} / \mathrm{m}^{3}$ respectively. In fibre-reinforced composites the average increase in strength was 90, 68, and $90 \%$ for the same dry unit weights.

It can be seen from the graphs presented in Fig. 3 that an increase of $\gamma_{\mathrm{d}}$ from 18 to $19.7 \mathrm{kN} / \mathrm{m}^{3}$ does not generate as great a strength gain as the increase in cement content does. This is being observed especially for the lowest cement content (3\%), where the increase in strength is 29 and $12 \%$ for unreinforced and reinforced composites respectively.

Considering the reduction of porosity, the strength gain rate for fibre-reinforced composites was smaller than for the unreinforced samples. The difference between unreinforced and reinforced composites is of 33, 18 and $7 \%$ for 18,19 and $19.7 \mathrm{kN} / \mathrm{m}^{3}$, respectively. The expected formation of bonds that higher compaction rates promote, also observed by Consoli et al. [14], is physically disrupted by the addition of fibres. It has been suggested that a greater compactive effort leads to greater entanglement and distortion of fibres which modifies the response of the reinforced soil [15]. 
Table 2. Flexural tensile test results for cemented sand.

\begin{tabular}{|c|c|c|c|c|c|c|}
\hline \multirow[b]{2}{*}{$\begin{array}{c}\text { Sampl } \\
\text { e }\end{array}$} & \multirow[b]{2}{*}{ 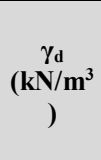 } & \multirow[b]{2}{*}{$\begin{array}{c}C \\
(\% \\
)\end{array}$} & \multirow[b]{2}{*}{$\begin{array}{c}F \\
(\% \\
)\end{array}$} & \multicolumn{3}{|c|}{ Max } \\
\hline & & & & $\begin{array}{c}\text { Repetito } \\
\text { n }\end{array}$ & $\begin{array}{c}\text { Loa } \\
\text { d } \\
(\mathbf{k N})\end{array}$ & $\underset{(\mathbf{k P a})}{\mathbf{q}_{\mathrm{f}}}$ \\
\hline 1 & \multirow{9}{*}{18} & 3 & 0 & $\mathbf{I}$ & 0.28 & 513.12 \\
\hline 2 & & 3 & 0 & II & 0.27 & 489.19 \\
\hline 3 & & 3 & 0 & III & 0.27 & 486.50 \\
\hline 4 & & 5 & 0 & I & 0.35 & 632.02 \\
\hline 5 & & 5 & 0 & II & 0.34 & 615.67 \\
\hline 6 & & 5 & 0 & III & 0.34 & 618.73 \\
\hline 7 & & 7 & 0 & I & 0.50 & 922.16 \\
\hline 8 & & 7 & 0 & II & 0.52 & 943.68 \\
\hline 9 & & 7 & 0 & III & 0.49 & 904.23 \\
\hline 10 & \multirow{12}{*}{19} & 3 & 0 & I & 0.35 & 628.90 \\
\hline 11 & & 3 & 0 & II & 0.35 & 637.58 \\
\hline 12 & & 3 & 0 & III & 0.35 & 626.33 \\
\hline 13 & & 5 & 0 & $\mathbf{I}$ & 0.49 & 896.81 \\
\hline 14 & & 5 & 0 & II & 0.51 & 930.88 \\
\hline 15 & & 5 & 0 & III & 0.51 & 933.18 \\
\hline \multirow{3}{*}{17} & & & 0 & & & 1062.1 \\
\hline & & 7 & \multirow{3}{*}{ 0 } & II & 0.58 & 1 \\
\hline & & & & & & 1030.8 \\
\hline \multirow[t]{2}{*}{18} & & 7 & & III & 0.57 & 4 \\
\hline & & & \multirow[t]{2}{*}{ 0 } & & & 1112.0 \\
\hline 28 & & 7 & & IV & 0.61 & 2 \\
\hline 19 & \multirow{14}{*}{19.7} & 3 & 0 & I & 0.34 & 611.61 \\
\hline 20 & & 3 & 0 & II & 0.37 & 676.63 \\
\hline 21 & & 3 & 0 & III & 0.35 & 625.80 \\
\hline \multirow[t]{2}{*}{22} & & 5 & 0 & I & 0.52 & 949.51 \\
\hline & & & 0 & & & 1012.3 \\
\hline 23 & & 5 & & II & 0.56 & 4 \\
\hline & & & 0 & & & 1030.3 \\
\hline 24 & & 5 & & III & 0.57 & 4 \\
\hline \multirow{3}{*}{25} & & & 0 & & & 1442.9 \\
\hline & & 7 & & I & 0.80 & 6 \\
\hline & & & 0 & & & 1399.9 \\
\hline \multirow[t]{2}{*}{26} & & 7 & & II & 0.77 & 5 \\
\hline & & & 0 & & & 1346.4 \\
\hline 27 & & 7 & & III & 0.74 & 0 \\
\hline
\end{tabular}

The great advantage of fibre addition to the composites is the modification of the failure mechanism. Fibre-reinforced composites presented a dramatic change from the brittle behaviour of cemented soil. The fibrereinforced specimens did not present a significant postpeak strength loss, rather, the strength remained constant for the duration of the test. Thus, the rupture mode can be considered as deflexion-hardening, as suggested by Donkor and Obonyo [10]. This failure mode modification can be qualitatively observed in Fig. 4, and corroborates the data presented by other authors for split tensile strength [7] and for flexural tensile strength [9]. The authors stress that fibres inhibit rupture associated cracks in fibre composites which leads to an increase in the area below stress-strain curve, representing a greater capacity for the composite to absorb energy.
Table 3. Flexural tensile test results for fibre-reinforced cemented sand.

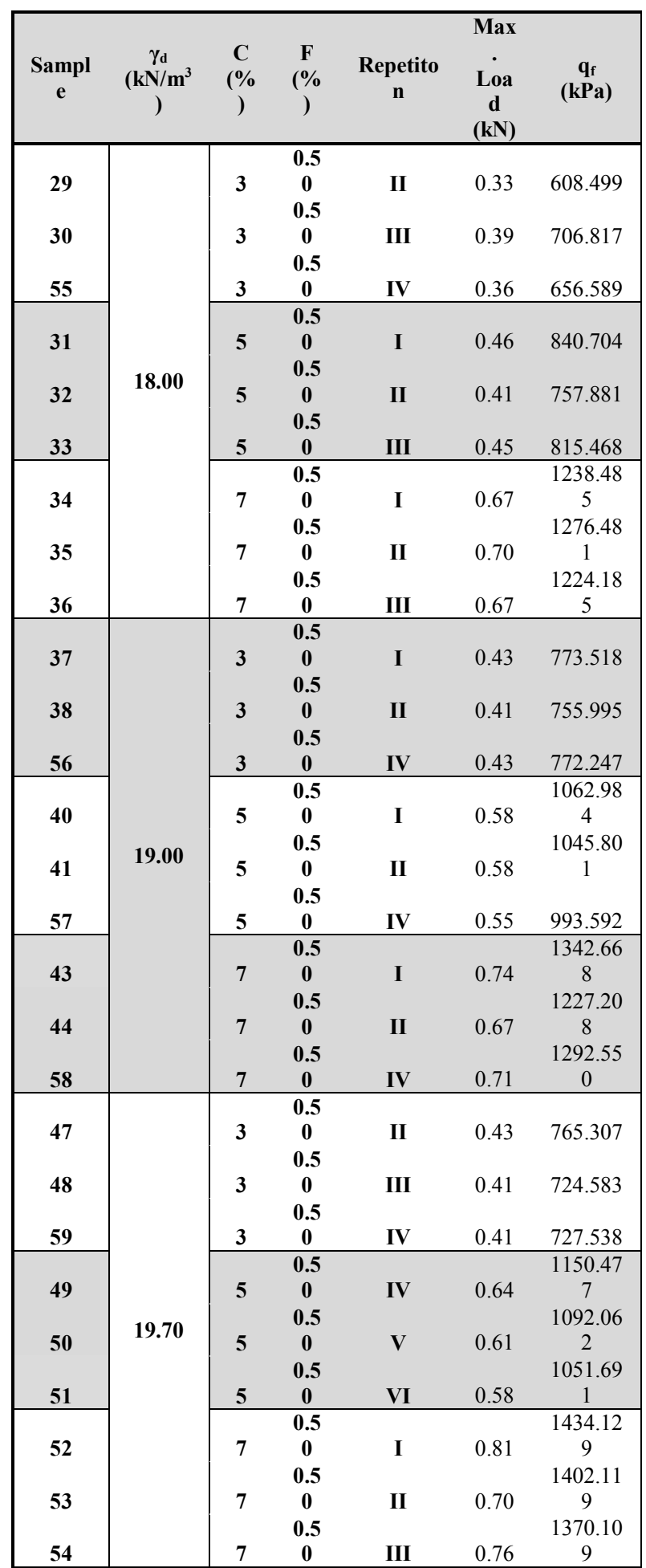




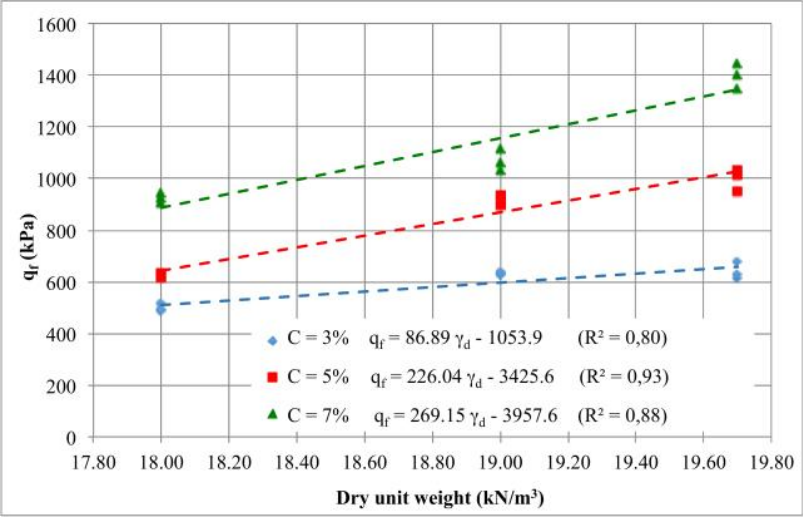

(a)

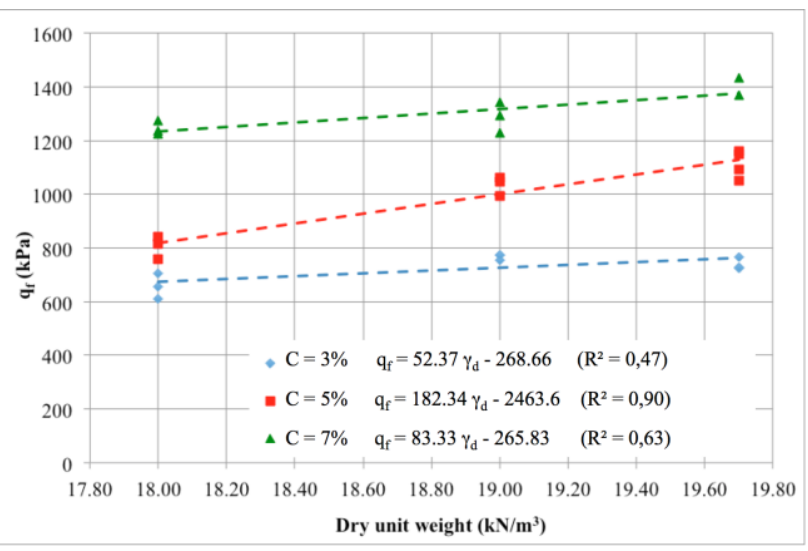

(b)

Fig. 3. Flexural strength of (a) cemented sand (b) fibrereinforced cemented sand

Fig. 5 presents the porosity $(\eta)$ versus volumetric cement content $\left(C_{I V}\right)$ ratio, presented as $\eta / C_{I V}$. The $\eta / C_{\text {IV }}$ ratio methodology is widely used in cemented soils to assess the mechanical resistance behaviour trends of cemented soils $[4,7,14,16]$.

The $\eta / C_{I V}$ ratio is analogue to the water/cement ratio used in concrete mixtures. In soil-cement mixtures, the voids are partially filled by water, not presenting a unique relationship between porosity and water content. Therefore, the use of a relationship between porosity and cement content is more appropriate [14]. The use of volumetric cement content $\left(\mathrm{C}_{\mathrm{IV}}\right)$ to express cement content presents a more elegant solution. Both $\eta$ and $C_{\text {IV }}$ are expressed as a percentage of the total volume of the sample, resulting in the dimensionless ratio [14].

The validity of using this methodology under the studied loading conditions for the used materials was tested and considered suitable. With high coefficients of determination $\left(\mathrm{R}^{2}\right)$ when used an exponent of 0.28 on the volumetric cement content $\left(\mathrm{C}_{\mathrm{IV}}\right)^{0.28}$ to equate the variation ratio between the porosity and the volumetric cement content against the flexural tensile strength $\left(\mathrm{q}_{\mathrm{f}}\right)$, as observed by $[7,16]$.

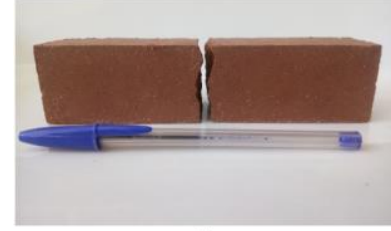

(a)

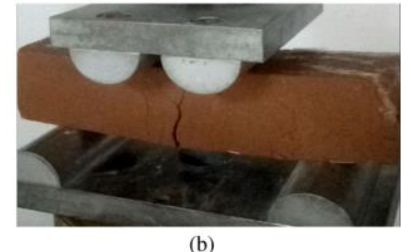

Fig. 4. Rupture mode (a) cemented sand - fragile (b) fibrereinforced cemented sand - ductile

Some important observations can be made from analysis of Fig. 5. For all studied mixtures there is an increase in flexural strength with the reduction in the $\eta /\left(C_{i v}\right)^{0.28}$ ratio, which implies that a reduction in the porosity and/or an increase in binder content leads to an increase in flexural tensile strength. Fibre insertion leads to an increase in flexural tensile strength for lower $\eta /\left(C_{i v}\right)^{0.28}$, however, as the $\eta / C_{i v}$ decreases, the impact of fibre addition on strength diminishes.

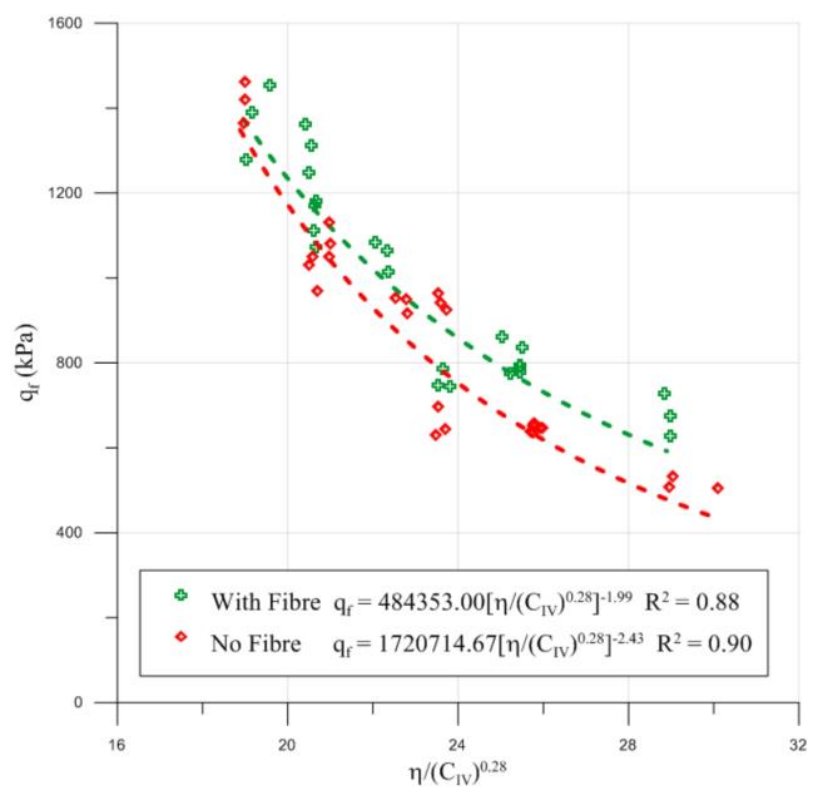

Fig. 5. Adjusted porosity/volumetric cement ratio for nonreinforced and reinforced cemented sand

\section{Conclusions}

From the data and analysis presented in this paper, the following conclusions can be drawn.

- Specimens subjected to flexural tensile tests presented an increase in tensile strength due to the increase in cement content. However, the increase in dry unit weight did not give the mixtures the same level of strength gains as the increase in cement content.

- The addition of randomly oriented fibres increased the tensile strength mainly for lower density samples. As the density of the specimen increased, the fibre contribution in tensile strength gain decreased. This can be attributed to an increase of entanglement and stretch of fibres in denser samples, disrupting the formation of cementitious bonds.

- The use of the porosity/volumetric cement content ratio can be used as a methodology for predicting 
tensile strength in flexural tests. When an exponent of 0.28 is used on the volumetric cement content, the data presents a good fit to previous research with the same material [7]. Exhibiting a high coefficient of determination for cemented soil and fibre-reinforced cemented soil.

- This research is part of a larger project studying the fatigue life of fibre-reinforced cemented sand composites. Therefore, the results presented on this research are of vital importance and will be used as a baseline when establishing the load percentage used for cyclic testing.

The authors wish to express their gratitude to the Brazilian Research Foundations CNPq and CAPES for their financial support of the research group. And to Lawrence de Leeuw for proofreading the paper.

\section{References}

1. K. Alhashimi, T. K. Chaplin. Geotechnique, 24, 541-550 (1973)

2. M. H. Maher, Y. C. Ho, Geotech. Testing J., 16, 330338 (1993)

3. N. C. Consoli, L. A. Ulbrich, P. D. M. Prietto, Int. Symp. On Recent Developments In Soil And Pavement Mechanics (Rotterdam: A.A. Balkema, 481-486, 1997)

4. N. C. Consoli, R. C. Cruz, M. F. Floss, L. Festugato, J. of Getotch. and Geoenv. Eng. 136, 759-763 (2010)

5. L. Li, R. Mitchell. Canadian Geotech. J. 25, 389-395 (1988)

6. S. R. Kaniraj, V. G. Havanagi. J. of Geotech. and Geoenv. Eng. 127, 574-584 (2001)

7. N. C. Consoli, R. R. Moraes, L. Festugato, Geosynthetics Int., 18, 57-62 (2011)

8. A. Kumar, D. Gupta. Geotextiles and Geomembranes. 44, 466-474 (2016)

9. P. Sukontasukkul, P. Jamsawang. Const. and Building Mat. 29, 201-205 (2012)

10. P. Donkor, E. Obonyo. Const. and Building Mat. 121, 25-33 (2016)

11. ABNT NBR 7182, Soil-Compaction test (1986)

12. ASTM D1635, Annual Book of ASTM Stand. 4 (2012)

13. L. P. Specht. Dissertation thesis, (Porto Alegre, Brazil, 2000).

14. N. C. Consoli, D. Foppa, L. Festugato, K. S. Heineck. J. of Geotech, and Geoenv. Eng. 133, 197 205 (2007)

15. D. H. Gray, T. Al-Refeai. J. of Geotech. Eng. 112, 804-820 (1986)

16. N. C. Consoli, M. A. Bassani, L. Festugato. Geotextiles and Geomembranes. 28, 344-351 (2010) 